Heruler. Deren Schicksal war Justinians Historiker Prokop, der sich in historiographischer Tradition sehr für die Randvölker interessierte, ein eigener Exkurs wert. ${ }^{3}$

Isaurische Räuber sind auch erwähnt in einem Brief der Mönche von Apamea, einem der palästinischen Sabbasklöster zwischen den Jahren 542 und 544. Allerdings handelt es sich hierbei um eine Sammlung von fingierten Briefen an Petrus Fullo (den „Walker"), den alten Patriarchen von Antiochia aus dem Jahrhundert zuvor, verfaßt von orthodoxen Mönchen wohl lateinischer Muttersprache, die sich in oder in der Nähe von Konstantinopel befanden. Aus Rücksicht auf ihre nur griechisch sprechenden Gegner, die palästinensischen und antiochenischen Mönche, schrieben sie griechisch. ${ }^{4}$ Die Sammlung dieser seltsamen Dokumente erlebte mehrere Auflagen und wurde zu guter letzt wiederum ins Lateinische rückübersetzt. ${ }^{5}$ Aus dieser problematischen Quelle läßt sich nicht auf etwaige räuberische isaurische Aktivitäten schließen.

\title{
2. Isaurische Soldaten in den Kriegen Iustinians
}

Mehr als ein Drittel des oströmischen Invasionsheeres im Jahr 535 nach Italien bestand aus Isauriern: Es befanden sich unter dem 8000 Mann starken Heer des Belisar 3000 Isaurier unter dem Kommando eines gewissen Ennes, die später noch um weitere 3000 Mann unter Paulus und Konon verstärkt wurden. ${ }^{6}$ Sie führten öfters Kriegsentscheidungen herbei: Isaurier entdeckten ein Loch im Aquädukt und machten so nach langer Belagerung die Eroberung von Neapel möglich, so daß Belisar noch im Sommer nach Rom gegen den Gotenkönig Theodahat weitermarschieren konnte. Dessen Nachfolger Totila konnte im Jahr 550 Rom ein weiteres Mal erobern, da die isaurische Besatzung, die keinen Sold erhalten hatte, die Tore öffnete. ${ }^{8}$ Auch im Perserkrieg kamen isaurische Kontingente unter eigener Führung durch Longinus, Ste-

(Pisidien), wo man diese Provinzen zunächst den „rauheren“ in der Verwaltungsreform voranstellen wollte, und auf das Edikt IV (aus den Jahren zwischen 535 und 541). Zu Justinian vgl. Rubin (1960); Moorhead (1994); Evans (1996).

3 Proc. $B G$ II 14.

4 ACO III, Collectio Sabbaitica, p. 107; SCHWARTZ (1934) 288.

5 Schwartz (1934) 296.

6 Proc. $B G$ I 5, 2f.; II 5, 1; PLRE III 441f., s.n. 'Ennes', 976 s.n. 'Paulus 5'; 331f., s.n. 'Conon 1'; vgl. Elton (2000b) 395. Auflistung der Stellen bei Minor (1979) 127, Anm. 59; ELTON (2000b) 395; LENSKI (1999a) 438, Anm. 134 ergänzt hierzu noch Euagr. h.e. V 16; Agathias III 20, 9; Jord. rom. 382; Mal. XVIII 26 p. 489. Insgesamt 55 mal sind Isaurier bei Prokop genannt, 5 mal bei Agathias: III 20, 9 (isaurische Schützen); IV 16, 2 (die Isaurier als leichtbewaffnete Truppen); IV 29, 2 (Parallele zwischen der Regierungszeit des Kabades und des Zeno hinsichtlich der Gefährdung ihrer Regierung durch Usurpation); V 15, 4 (Rekrutierung von Isauriern in der Palastgarde durch Zeno).

7 Proc. $B G$ I 9, 8-21.

8 Proc. $B G$ III 36f.; DEMANDT (1989) 206; ELTON (2000b) 395. 
phanacius, Dorotheus und Mamas, die teilweise zu Belisars Leibwache gehörten, zum Einsatz. $^{9}$

Die Isaurier stellten jedoch keineswegs immer die kampferprobten Truppenteile und Leibgarden, sondern sie wurden des öfteren alle im Gefecht niedergehauen, ohne Gegenwehr geleistet zu haben, da sie ,vom Pflug weg" rekrutiert worden waren. ${ }^{10}$ Die Rekrutierung isaurischer Hilfstruppen setzte sich in der byzantinischen Zeit fort: Im Perserkrieg des Caesars Tiberios Konstantinos unter Justin Il. im Jahr 575 kämpften Isaurier. "1

Die isaurischen Regimenter in Justinians Armee sind eher ein Beleg für die Gleichstellung mit anderen Föderatentruppen, unterschiedslos z. B. zu den hunnischen, als für eine gelungene Rückintegration. Ihre Bezeichnung und Nennung im Kontext mit anderen Barbaren läßt sie als Fremdkörper erscheinen; die Isaurier sind nun gleichsam Gastarbeiter wie die übrigen Barbaren in einem Heer, das ohnehin kaum mehr aus „Rhomäern“ bestand.

\section{Isaurische Baumeister?}

Nicht nur als Soldaten in Justinians Armeen, sondern auch als Wanderarbeiter treten die Isaurier seit dem frühen 6. Jahrhundert auf. ${ }^{12}$ Ihrer Existenz wird von einigen Forschern als Argument für eine erneute Integration in das Reich als Vollbürger ge-

9 Proc. BP I 18, 5 (ein zehntel Isaurier, 2000). 7 (Longinus und Stephanacius); Mal. XVIII 60 p. 463f. (Z. 21: Dorotheus und Mamas); PLRE III 795 s.n. 'Longinus 1', 1183 s.n. 'Stephanacius', 421 s.n. 'Dorotheus 4', 808f., s.n. 'Mamas'; Mal. XVIII 26 p. 441 f; Agathias II 20, 9; Euagr. h.e. V 14 (Isaurier).

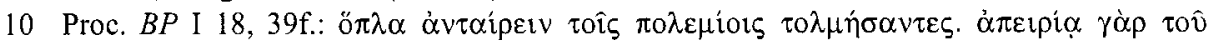

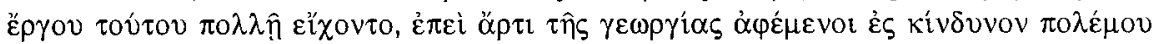

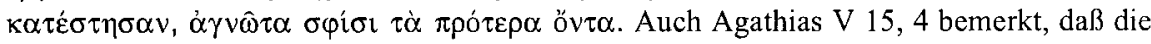
schon von Zeno in Dienst genommenen Isaurier über keinerlei militärische Qualifikation verfügten. Eine zweite Version der Expositio, die wohl nach den Erfolgen des Justinian entstanden ist, schreibt dann auch einfach Isauria quae viros fortes et latrocinantes emittit; ROUGÉ (1966) 312f., Anm. 8.

11 DitTen (1993) 127. Daß die von Prokop explizit so genannten isaurischen Regimenter ausschließlich aus Isauriern bestanden, bezweifelt ELTON (2000a) 295. (2000b) 395 mit Hinweis auf die kappadokische Abstammung des in der V. Sabae des Cyrill Scythopolitanus genannten Konon, s.o. Kap. V.1.1.

12 Holl (1904) 21 u. Anm. 2: Verweis auf den Brief des Gregor von Nyssa ep. 25, ed. Pierre Maraval, SC 363, Paris1990, an Amphilochius von Iconium mit der Bitte um Fach-

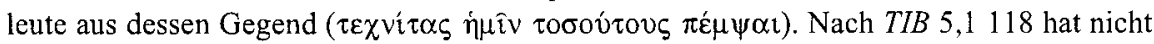
unbedingt wirtschaftliche Not die isaurischen Wanderhandwerker in die Antiochene getrieben, es kann sich auch um Spezialisten gehandelt haben, deren Wissen besonders nach den Erdbeben gefragt war. 